
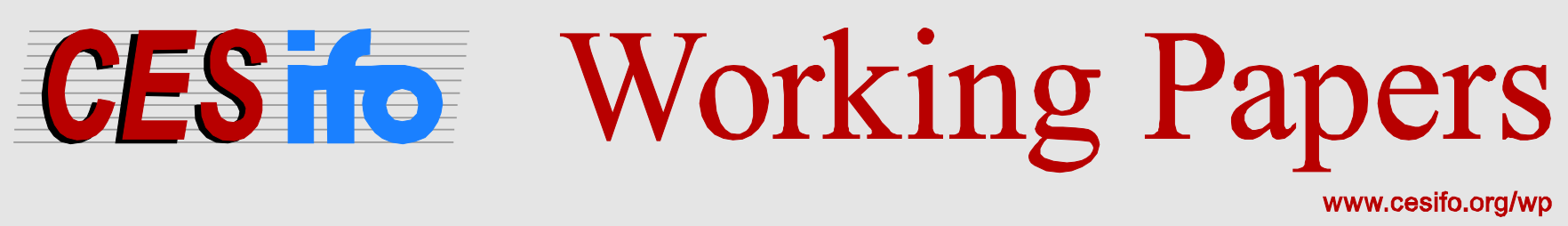

\title{
Green Tradable Certificates versus Feed-in Tariffs in the Promotion of Renewable Energy Shares
}

\section{Till Requate}

\author{
CESIFO WORKING PAPER NO. 5149 \\ CATEGORY 10: ENERGY AND ClimATE ECONOMICS \\ DECEMBER 2014
}

Presented at CESifo Area Conference on Energy and Climate Economics, October 2014

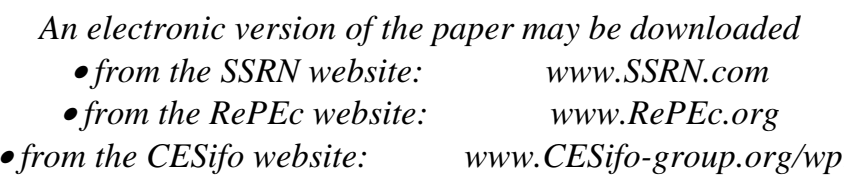




\title{
Green Tradable Certificates versus Feed-in Tariffs in the Promotion of Renewable Energy Shares
}

\begin{abstract}
The paper analyzes the relationship between CO2 mitigation policy and promotion policies designed to deploy renewable energy sources for electricity production (RES-E). If an emission cap is the only policy target, an optimal mix consisting of high and low carbon use of fossil fuels, deployment of RES-E, and energy savings can best be achieved by either setting a uniform carbon tax or by implementing a cap-and-trade system covering all $\mathrm{CO} 2$ sources. An additional RES-E share target causes higher costs in achieving the cap. Conversely, a more ambitious emission target automatically increases the RES-E share. In a second step we investigate different policies for inducing an RES-E quota. Such a quota can be efficiently achieved either by a system of tradable green certificates or by a budgetbalancing premium system. A budget-balancing FIT system, by contrast, is not efficient, since it generates excessive fiscal distortion. We also show that differentiated, technology-specific FITs are even more inefficient.
\end{abstract}

JEL-Code: L380, L510, L940, Q280, Q420, Q550.

Keywords: feed-in tariffs, tradable green certificates, premium systems, emission cap, cap and trade.

\author{
Till Requate \\ Kiel University \\ Department of Economics \\ Olshausenstrasse 40 \\ Germany - 24118 Kiel \\ requate@economics.uni-kiel.de
}

December 15, 2014

I am grateful to Christoph Böhringer, Mathis Klepper, Matthias Weitzel, and two anonymous referees for helpful comments, and Stacy VanDeveer for information on overlapping US carbon policies. 


\section{Introduction}

For the period 2008-2012, Annex I countries that have ratified the Kyoto protocol are committed to an average reduction of their $\mathrm{CO}_{2}$ emissions to $5.2 \%$ below the 1990 level. Broadly speaking, there are four ways of achieving this target: reducing the output of primary and secondary energy use and of other $\mathrm{CO}_{2}$-intensive products, enhancing energy efficiency (i.e. producing the same amount of output with less carbon input), substituting low-carbon fossil fuels (such as natural gas) for carbon-intensive fuels (like lignite and hard coal), and generally replacing fossil fuels by increasing the share of renewable energy sources (RES). An efficient mix of all these measures would be the optimal solution. To make the allocation of such $\mathrm{CO}_{2}$ reduction efforts work, the marginal opportunity costs of all these measures have to be equal. Following this rule, $\mathrm{CO}_{2}$ reductions will be maximal given a fixed amount of financial resources. To meet their joint target at the lowest possible cost, signatory countries could implement a rigorous cap-and-trade system (or charge a corresponding uniform carbon tax) covering all their $\mathrm{CO}_{2}$ sources. If the whole world implemented a cap-and-trade system (or a uniform carbon tax) covering all sources of carbon, that of course would be better still.

Looking at the different measures countries opt for in their attempts to curb $\mathrm{CO}_{2}$ emissions, we observe quite an array of different policy instruments, some used alternatively, others in an overlapping way. In the USA, for instance, a nationwide $\mathrm{CO}_{2}$ cap-and-trade system seems politically impracticable at the moment, with the upshot that an increasingly

complex set of policy measures has evolved at state level. They encompass renewable 
portfolio standards, various energy efficiency programs, and (output) taxes on electricity or fuels (labeled "public benefits charges") to generate revenues for energy efficiency programs and subsidies. In addition, states like California or groups of states in the north-east (headed by NY, MA, CT) have implemented local carbon-trading schemes, such as the Regional Greenhouse Gas Initiative (RGGI). Other states have implemented different schemes for using RES (renewable energy sources), notably for generating electricity (RES-E). ${ }^{2}$

By contrast, Europe's major carbon policy is the EU-ETS, a $\mathrm{CO}_{2}$ emission cap-andtrade scheme covering roughly half of the continent's overall $\mathrm{CO}_{2}$ emissions, including all emissions from major power plants and carbon-intensive industries. As a supplementary policy, the European Commission has also initiated the 20-20-20 target, meaning that by 2020 $\mathrm{CO}_{2}$ emissions are to be reduced by $20 \%$, energy efficiency increased by $20 \%$, and the share of RES stepped up to $20 \%$. Ignoring the problem of international carbon leakage for a moment, we can say that the spirit of Kyoto revolves around the emission reduction goal. But it is less obvious why the other two targets (increasing energy efficiency and implementing a particular share of RES) are necessary to achieve this overall emission reduction. In fact, it is far from clear whether these two sub-targets would be the spin-off from efficient allocation designed to achieve the main goal (a 20\% emission reduction). If they were, a cap-and-trade scheme would automatically bring about the achievement of these goals. If they were not, the sub-targets would only increase the cost of achieving the actual emission reduction target.

Besides the main goal of curbing greenhouse gases, the EU directive on the promotion of the use of energy from renewable sources names other objectives of this policy, notably lowering dependence on fossil fuel imports, creating new employment opportunities, triggering green growth, and promoting competition on the electricity market (EC, 2009). However, these additional objectives are highly questionable. Take the lowering-importdependence argument. Except for oil, which plays almost no role in electricity production,

\footnotetext{
${ }^{2}$ For details, see Selin and VanDeever (2009).
} 
fossil fuel resources are - unfortunately for the greenhouse problem - abundant and ubiquitous. In the last few decades, coal prices have increased only modestly and, due to the discovery of new deposits and new methods of exploitation, gas prices have even gone down. From the theory of exhaustible resources we know that if social and market interest rates coincide, if resources come under private property, and if resource markets are competitive, then the market extraction path induced by the market will also be socially optimal and there will be no market failure. Therefore, if we were not facing the greenhouse problem, there would be little need to intervene in the market and artificially reduce fossil fuel imports. The employment and growth arguments also stand on shaky foundations. We will discuss these objectives in more detail in section 7.

Even if we take it as both self-evident and politically desirable that fossil fuels be salvaged, the question is how to implement such a target in a cost-efficient way. To achieve the $20 \%$ RES share target in all energy use, various countries use different policies to increase the share of RES-E. These policies divide roughly into two classes, quantity-based and pricebased. We refer to quantity-based policies if a certain share of RES-E is compulsory for electricity utilities. Nationwide (or worldwide), such a share can be implemented in a costefficient way by implementing a system of tradable green certificates (TGCs). This means that utilities (or private owners of RES-E equipment) exceeding the required share of RES-E can apply for certification of RES-E electricity units and sell these to electricity producers unable to meet the required target on their own (or only at a prohibitively high cost). Two main types of price instrument exist, the feed-in tariff system and the premium system. The latter, as implemented in Spain, works like a customary subsidy. RES-E electricity producers receive a premium (i.e. a subsidy) in addition to the market price, they are thus also exposed to market-price volatility and can react to supply and demand. In a feed-in tariff system, as originally implemented in Denmark, the Netherlands and Germany (62 other countries have now followed suit), RES-E electricity producers receive a guaranteed feed-in price 
independently of market prices. Electricity producers using RES are thus completely divorced from supply and demand, and grid operators have to buy RES-E electricity even if there is excess supply and the market price has become negative.

In the feed-in tariff system as implemented in Germany (and other countries), there is indeed a guaranteed feed-in price, but the system is also discriminatory. Feed-in tariffs are technology-specific. The higher the unit cost of electricity production using a specific technology, the higher the feed-in tariff. Supporters of the discriminatory system put forward different arguments to justify this policy. One such argument is that the government has to boost learning-by-doing. By subsidizing high-cost technologies, cost can be brought down to competitive levels. The second, quite different argument is that a discriminatory system leads to low rents for both RES-E operators and RES-E equipment producers, thus keeping the social cost of subsidization low.

In this article, we analyze both $\mathrm{CO}_{2}$ emission reduction and RES-E share policies. We start by recalling that if an emission cap is the only policy target, an optimal mix consisting of high and low carbon use of fossil fuels, deployment of RES-E and energy savings can best be achieved by either setting a uniform tax for $\mathrm{CO}_{2}$ or by implementing a cap-and-trade system covering all $\mathrm{CO}_{2}$ sources. An additional RES-E share target only makes it more expensive to achieve the emission cap. We also show that more ambitious emission targets lead to higher prices for both emissions and electricity and thus to lower output (i.e. higher electricity savings). A more ambitious target also automatically increases the share of RES-E and lowers the share of carbon-intensive fossil fuels. By contrast, the impact on low-carbon fossil fuels like natural gas is ambiguous. In a second step, we investigate how a uniform feed-in tariff (FIT) impacts on the crucial endogenous variables. For this purpose, we distinguish between an FIT financed in a lump-sum way (or by raising distortionary taxes elsewhere in the economy) and one that is financed by a mark-up on the electricity price. In the first case (lump sum finance), increasing the uniform feed-in tariff does precisely the wrong thing. It 
leads to lower electricity prices and thus provides smaller incentives for households and industry to save energy. Such a policy clearly increases the share of RES-E, which is desirable. But it overshoots the mark, since it also crowds out low-carbon fossil fuels. If the FIT is financed by a mark-up on the electricity price, the effect will be similar. While the overall impact on total output and prices is ambiguous, electricity prices are indeed likely to increase.

The third issue we shall be investigating is RES-E quotas. Our findings indicate that increasing the RES-E quota crowds out all fossil fuels including the low-carbon varieties, which is not necessarily efficient. The impact on total output is also ambiguous.

Accepting a politically set RES-E quota, however, we show that such a quota can be efficiently decentralized by implementing a system of tradable green certificates (TGCs). The quota can equivalently be decentralized by a budget-balanced premium system where RES-E operators receive a premium on top of the market price and the premium is financed through a mark-up on the electricity price. A budget-balanced FIT system, by contrast, is less efficient since it creates a fiscal distortion through excessive electricity prices.

We also discuss differentiated, technology-specific feed-in tariffs. Given a fixed share of RES-E, an increase in the tariff for high-cost electricity coupled with a reduction in the tariff for low-cost electricity will clearly lower the share of low-cost RES-E and increase the share of high-cost RES-E, thus rendering electricity production from RES-E altogether more costly and less efficient. The impact on the electricity-price surcharge and hence on the final price paid by consumers and industry is ambiguous. This finding contrasts with the claims typically put forward by the champions of technology-specific feed-in tariffs, who argue that these tariffs lower producer rents in the RES sector and are therefore beneficial for consumers.

Finally, we scrutinize the learning-by-doing argument, contending that, if learning effects are purely private (i.e. there are no learning spill-overs), FITs are not necessary or 
should simply be equal to the market price for electricity. Only if there are learning effects that differ across technologies can a differentiated technology-specific FIT system be justified. However, in contrast to current practice, the FITs should be paid according to the marginal spill-over effects, not the current marginal cost of production. Private learning effects are (or should be) taken into account by RES equipment and electricity producers.

There is a vast literature on the pros and cons of FITs and other climate policies. Many of the items in it are however anything but rigorous and are frequently based on unreliable theoretical foundations. Auer et al. (2009), Haas et al (2004, 2010), Held et al. (2006) and others argue in favor of technology-specific FITs. Their main point is that such a differentiated system lowers producer rents and is better at reducing electricity prices than either a uniform FIT or a market TGCs. Mitchell et al. (2006) also favor FITs for the protection of RES-E generators from market hazards, thus shifting the risk from the green electricity producers to society. Klessmann et al. (2008) argue that a FIT system protects RES-E against market risk. By contrast, Midttun and Gautesen (2007) argue in favor of a cross-European TGC system.

Jensen and Skytte (2002) study the interaction between the electricity output market and TGC markets. They argue that TGCs are not the right instrument for the deployment of RES-E. Zhou and Tamas (2010) investigate the interaction between TGCs and the output markets in the presence of market power. In a follow-up paper, Tamas et al. (2010) show that even under imperfect competition, uniform FITs and green certificates are equivalent. Morthorst $(2003 \mathrm{a}, \mathrm{b})$ studies TGC markets in a multi-country model. In contrast to our conclusions, he argues that a combination of a $\mathrm{CO}_{2}$ permit market and TGCs might be efficient in achieving national $\mathrm{CO}_{2}$ reduction targets.

Both Bläsi and Requate (2009) and Reichenbach and Requate (2012) study FITs and learning effects in the RES-E equipment industry. For both competitive and imperfectly competitive markets they show that pure learning effects do not warrant subsidies. Only if 
there are learning spillovers do subsidies for the RES-E equipment industry make sense, while FITs turn out to be inefficient. The authors draw on Petrakis et al. (1997), who show that the presence of purely private learning effects does not bring about market failure.

This article is organized as follows: In the next section we set up the elements of a formal model. In section 3 we study a pure emission target and instruments for achieving it. In section 4 we investigate how to achieve a quota for renewable energy in an efficient way. In section 5 we study differentiated industry-specific feed-in tariffs. In section 6 we discuss the implications of learning-by-doing effects. In section 7 we briefly discuss other objectives that are often put forward to justify the promotion of renewable energy sources, and in section 8 we draw some conclusions and indicate various avenues that further research might usefully explore.

\section{Ingredients for a Model}

We consider a partial model with electricity as a homogeneous good. Aggregate demand for electricity is represented by a downward-sloping inverse demand function $P(Q)$, where $Q$ is the total market quantity. This (inverse) function covers all demand from consumers and the factor demand from other industries.

We assume that there are two main sources of electricity: fossil fuels inducing $\mathrm{CO}_{2}$ emissions and renewable, emission-free energy. ${ }^{3}$ We refer to the former as conventional and to the latter as renewable energy resources for electricity (RES-E) technologies. We further assume there are $j=1, \ldots, J$ conventional technologies, and we use $C_{c j}\left(q_{c j}\right)$ to denote their cost functions for producing $q_{c j}$ units of electricity, with $C_{c j}{ }^{\prime}>0$ and $C_{c j}{ }^{\prime \prime}>0$. Furthermore we use $\alpha_{c j}$ to denote the emission coefficients of the conventional technologies. In addition,

\footnotetext{
${ }^{3}$ To keep things simple, we neglect the fact that the production of RES-E equipment itself may generate $\mathrm{CO}_{2}$ emissions. See Abbasi and Abbasi (2000) and Tsoutsos, et al. (2005) on negative environmental impacts from RES-E equipment production.
} 
there are $i=1, \ldots, I$ RES-E technologies, where $C_{r i}\left(q_{r i}\right)$ represents the cost of producing $q_{r i}$ units of electricity with RES-E technologies. Here we also assume $C_{r i}{ }^{\prime}>0$ and $C_{c i}{ }^{\prime \prime}>0$.

One might wonder how a wind turbine or a PV panel can incur increasing marginal costs. While there are no direct costs of operation, there is typically the cost of maintenance, and the more frequently maintenance is done, the better performance will be. More importantly, the interpretation of such a cost function is not that of a single unit but rather of a whole technology sector encompassing on-shore wind power, off-shore wind power, biogas, photovoltaic panels (PV), etc. In the case of wind power, turbines located close to the shore are more effective than those set up in the countryside far away from the coast (Menanteau et al.; 2003). With PV panels, sites in Southern Europe are typically more effective than those in the North. In this sense, there are indeed increasing marginal costs, since at less-favored locations more RES-E units need to be installed to produce the same quantity of output (electricity) than at good locations.

In many cases it is of course useful to look at a full disaggregate model. In other cases it is convenient to take a more aggregate view. In doing so, we assume that there are two types of technology employing fossil fuels: (a) emission-intensive base-load electricitygeneration technologies with total output denoted by $Q_{b}$ (typically coal-fired power plants) and (b) low-emission, flexible technologies used for peak-load electricity production with total output denoted by $Q_{f}$ (typically power plants fired by natural gas). Finally, total electricity output from renewable energy is denoted by $Q_{r}$. Thus total electricity output is given by $Q=Q_{b}+Q_{r}+Q_{f}$.

In this aggregate case we use $C_{b}\left(Q_{b}\right), C_{f}\left(Q_{f}\right)$, and $C_{r}\left(Q_{r}\right)$ to denote the cost functions of the three sources: base-load, flexible peak-load, and RES-E. By writing $C_{r}\left(Q_{r}\right)$ we assume that total output of renewable energy is allocated efficiently among all generation 
facilities, i.e. $C_{r j}{ }^{\prime}\left(q_{r j}\right)=C_{r k}{ }^{\prime}\left(q_{r k}\right)$ for all $j, k=1, \ldots, J$ with $Q_{r}=\sum_{j=1}^{J} q_{r j}$ and analogously for $C_{b}\left(Q_{b}\right)$ and $C_{f}\left(Q_{f}\right)$. With distorting policies, such an efficient allocation will not necessarily occur. We will come back to this point later.

The properties of the disaggregate cost functions $C_{c j}\left(q_{c j}\right)$ and $C_{r j}\left(q_{r j}\right)$ transfer to the aggregate case, i.e. aggregate marginal production costs are increasing and convex. More particularly, we assume strict convexity for all sources, i.e. $C_{j} "\left(Q_{j}\right)>0$ for $j=b, f, r$. Here again we use $\alpha_{b}>0$ and $\alpha_{f}>0$ to denote the emission coefficients of the two fossil-fuel technologies, and we assume $\alpha_{b}>\alpha_{f}$ to reflect the fact that the base load is typically served by $\mathrm{CO}_{2}$-intensive coal, whereas flexible power plants usually employ gas, which is less $\mathrm{CO}_{2}$ intensive. RES-E is assumed to be emission-free. ${ }^{4}$

To account for the social damage from $\mathrm{CO}_{2}$ emissions, one might introduce a social damage function. In the case of $\mathrm{CO}_{2}$, however, the damage accruing to a particular country from its own domestic emissions is relatively small, so domestic $\mathrm{CO}_{2}$ mitigation policies would not stand up to a cost/benefit analysis. For this reason we assume that a government will aim at achieving an aggregate emission target $\bar{E}$.

\section{Emission Target}

We begin by considering the situation where the government's only target is to reduce $\mathrm{CO}_{2}$ emissions. We are looking for the most efficient way to employ different types of energy to achieve an aggregate emission target, so the (domestic) social planner's problem is to maximize welfare given by

\footnotetext{
${ }^{4}$ As Abbasi and Abbasi (2000) and Tsoutos et al. (2005) point out this need not be the case.
} 


$$
W\left(q_{c 1}, \ldots, q_{c J}, q_{r 1}, \ldots, q_{r I}\right)=\int_{0}^{Q} P(\tilde{Q}) d \tilde{Q}-\sum_{j=1}^{J} C_{c j}\left(q_{c j}\right)-\sum_{i=1}^{I} C_{r i}\left(q_{r i}\right)
$$

where $Q=\sum_{j=1}^{J} q_{c j}+\sum_{i=1}^{I} q_{r i}$ is total output subject to the emissions constraint

$$
\sum_{j=1}^{J} \alpha_{c j} q_{c j} \leq \bar{E}
$$

The first-order complementary slackness (or Kuhn-Tucker) conditions for the conventional technologies are then given by

$$
P(Q)-C_{c j}{ }^{\prime}\left(q_{c j}\right)-\lambda \alpha_{c j} \leq 0, \quad\left[P(Q)-C_{c j}{ }^{\prime}\left(q_{c j}\right)-\lambda \alpha_{c j}\right] q_{c j}=0
$$

while for the RES-E technologies we obtain

$$
P(Q)-C_{r i}{ }^{\prime}\left(q_{r i}\right) \leq 0, \quad \text { and } \quad\left[P(Q)-C_{r i}{ }^{\prime}\left(q_{r i}\right)\right] q_{r i}=0
$$

Here we see that for the RES-E technologies the equal marginal cost principle holds, i.e.

$$
C_{r i}{ }^{\prime}\left(q_{r i}\right)=C_{r k}{ }^{\prime}\left(q_{r k}\right)=P(Q)
$$

This means that for all sources producing positive quantities it should be equally expensive to produce the last unit of electricity, and marginal costs should be equal to the consumers' marginal willingness to pay, thus making them equal to the competitive market price. Only if $P(Q)-C_{r_{0}}{ }^{\prime}(0) \leq 0$ holds for some technology $i_{0}$ should this technology not be employed at all.

For the conventional technologies we obtain

$$
\frac{P(Q)-C_{c j}{ }^{\prime}\left(q_{c j}\right)}{\alpha_{c j}}=\frac{P(Q)-C_{c k}{ }^{\prime}\left(q_{c k}\right)}{\alpha_{c k}}
$$

for all $j, k$. We can interpret both sides of (6) as the marginal abatement costs of technology $j$ and $k$, respectively. This is the gap between the consumers' marginal willingness to pay and the pure marginal production cost. This difference is then divided by the respective emission coefficients. Thus (6) requires the marginal abatement cost to be equal for all polluting electricity-generating technologies. We can summarize this well-known result as follows: 
Proposition 1: Assume there is an emission target only. Then optimal allocation between conventional and renewable electricity production requires RES-E sources to produce at equal marginal cost and to be equal to consumers' marginal WTP, while conventional technologies should produce at equal marginal costs reflecting the private marginal production cost of electricity production plus the uniform shadow price for the emission target.

\subsection{The impact of tightening the emission cap}

It is worth looking briefly at how a tighter emission cap impacts on the employment of the three types of electricity output. For this purpose, we look at the more aggregate model, writing welfare as

$$
W\left(Q_{b}, Q_{r}, Q_{f}\right)=\int_{0}^{Q} P(\tilde{Q}) d \tilde{Q}-C_{b}\left(Q_{b}\right)-C_{f}\left(Q_{f}\right)-C_{S}\left(Q_{S}\right)
$$

The first-order conditions for socially optimal allocation are then given by

$$
\begin{aligned}
& P(Q)=C_{b}{ }^{\prime}\left(Q_{b}\right)+\lambda \alpha_{b} \\
& P(Q)=C_{f}{ }^{\prime}\left(Q_{f}\right)+\lambda \alpha_{f} \\
& P(Q)=C_{r}{ }^{\prime}\left(Q_{r}\right) \\
& \alpha_{b} Q_{b}+\alpha_{f} Q_{f}=\bar{E}
\end{aligned}
$$

Differentiating (7) - (10) with respect to $\bar{E}$, we arrive at the following result:

Proposition 2: Assuming that the emission cap is binding and there is an interior solution for all three kinds of energy sources, then

$$
\frac{d Q_{b}}{d \bar{E}}>0, \quad \frac{d Q_{r}}{d \bar{E}}<0, \quad \frac{d Q}{d \bar{E}}>0, \quad \frac{d p}{d \bar{E}}<0, \quad \frac{d \lambda}{d \bar{E}}<0, \quad \frac{d}{d \bar{E}}\left(\frac{Q_{r}}{Q}\right)<0
$$

By contrast, the sign of $\frac{d Q_{f}}{d \bar{E}}$ is ambiguous. 
For a proof, see the appendix. We see that relaxing (tightening) the cap leads to less (more) employment of renewable energy, while pollution-intensive base-load electricity increases (decreases). The impact on flexible conventional electricity (natural gas) is ambiguous, whereas total electricity output (and therefore also the total amount of electricity generated from fossil fuels) increases (decreases). The consumer price decreases (increases). Importantly, the share of renewable energy also falls (increases)! The direction of the results is as we would expect. Note that the amount of flexible energy $Q_{f}$ going up or down with the emission cap depends mainly on the difference in the emission coefficients. If $\alpha_{f}$ is only slightly smaller than $\alpha_{b}$, both types of fossil fuel electricity output will be reduced as the emission cap is set more stringently. If flexible energy is considerably less $\mathrm{CO}_{2}$-intensive than base-load energy, the flexible energy will increase and crowd out base-load energy as the emission cap gets tighter.

\subsection{Decentralization by emission taxes or tradable permits}

It is well known that, if energy markets are perfectly competitive, the first-best allocation with an emission cap can be decentralized either by implementing a cap-and-trade system (with an aggregate supply of tradable permits equal to $\bar{E}$ ) or by charging an emission tax equal to the optimal shadow price of pollution $\lambda$.

\subsection{Feed-in tariff with lump-sum financing of subsidies}

It is usually argued that FITs (or other policies promoting renewable energy) are needed because generating electricity by means of environmentally friendly RES-E is more costly than employing fossil fuels, and that RES-E would otherwise have a competitive disadvantage as long as emissions are not priced appropriately (e.g. Menanteau et al. 2003). Against this background, it is natural to ask how FITs perform in reducing emissions. There are basically 
two different ways in which FITs are financed. In the past, some countries such as Denmark and the Netherlands have financed FITs via the state budget, i.e., money for subsidies has been collected by raising other, usually distorting taxes. In other countries such as Germany, the money paid to RES-E operators is collected through a budget-balancing mark-up on the electricity price. Although seemingly equivalent at first glance, the two systems differ considerably. In the first case (financing via state budget), an increase in the FIT has a negligible impact on the electricity price, while in the second case both increasing the FIT and extending RES-E capacity directly affects that price. ${ }^{5}$ We will first study financing through the state budget.

For simplicity, we stick to the aggregate version of the model. We assume that RES-E suppliers receive a FIT instead of being exposed to the market price ${ }^{6}$ and that the money financing the subsidies is collected from the consumers in a lump-sum way (ignoring further burdens by other distorting taxes). Denoting the FIT rate by $\zeta$, the competitive market equilibrium is given by

$$
\begin{gathered}
P(Q)=p=C_{b}{ }^{\prime}\left(Q_{b}\right) \\
P(Q)=p=C_{f}{ }^{\prime}\left(Q_{f}\right) \\
\zeta=C_{r}{ }^{\prime}\left(Q_{r}\right)
\end{gathered}
$$

The next result shows how an increase in the FIT impacts on the allocation.

Proposition 3: Assume the electricity market is fully competitive. Then an increase in the FIT leads to

\footnotetext{
${ }^{5}$ In Germany, the FIT mark-up was $3.59 €$ cents per kwh in 2012. By 2014 the mark-up increases by $47 \%$ to $6.27 €$ cents per kwh. (www.bmwi.de). If the still low share of off-shore wind-power capacity is further increased, an additional sharp increase in the mark-up is likely to occur.

${ }^{6}$ An institutional setting of this kind is used in Germany, for example. It is also possible to pay a tariff in addition to the market price (premium model), as is the case in Spain. In the absence of uncertainty, these two regimes are equivalent. The premium naturally differs in size from the FIT.
} 


$$
\frac{d Q_{b}}{d \zeta}<0, \frac{d Q_{f}}{d \zeta}<0, \frac{d Q_{r}}{d \zeta}>0, \frac{d Q}{d \zeta}>0, \frac{d p}{d \zeta}<0, \frac{d}{d \zeta}\left(\frac{Q_{r}}{Q}\right)>0 \frac{d E}{d \zeta}<0
$$

where $E=\alpha_{b} Q_{b}+\alpha_{f} Q_{f}$ represent emissions.

For a proof, see the appendix. Renewable energy thus crowds out fossil fuels, which at first glance would seem to be a desirable outcome. Total fossil-fuel electricity output goes down, so emissions will also go down, and the share of renewable energy will increase. However, the FIT is less efficient than an emission cap since the less polluting fossil-fuel input (e.g. natural gas) is not used efficiently. An increase in the FIT also unambiguously lowers the relatively environmentally friendly employment of flexible energy (natural gas), while a more stringent emission cap would not necessarily crowd out that kind of energy. Moreover, through a decrease in both types of fossil fuels, emissions also go down, which is a desirable effect. However, total electricity output increases and the electricity price decreases. This differs widely from the emission-cap scenario, where a tighter emission cap leads to less output and thus a higher pric. Accordingly, under a FIT, and in contrast to a cap-and-trade system, consumers do not contribute to the energy-saving opportunities induced by increasing the electricity price and hence make no contribution to enhancing energy efficiency. This would make it more difficult to achieve the third 20-20-20 target of enhancing energy efficiency by $20 \%$. Thus a FIT financed through the state budget creates an additional source of inefficiency. Since consumers have to pay for the subsidy (in our model in a lump-sum way), they are also hurt by that inefficiency.

\subsection{Feed-in tariffs financed by a mark-up on the electricity price}

We now change the institutional setting by assuming that expenditures for the subsidies are collected from the consumers via a mark-up on the electricity price, as is the case in most European countries. In such a setting the grid owners have to purchase the "green" electricity 
from RES-E operators and sell it on the spot market at market the clearing price. Since the FIT typically exceeds the market price, there will be a deficit which has to be financed by a surcharge on the electricity price, or equivalently, by an implicit tax on conventional electricity. We stay with the aggregate version of the model. Accordingly, the representative competitive suppliers of fossil-fuel electricity earn the following profit:

$$
\pi=(p-t)\left[Q_{b}+Q_{f}\right]-C_{b}\left(Q_{b}\right)-C_{f}\left(Q_{f}\right)
$$

where $t$ is the contribution conventional fossil-fuel utilities have to make to cover the expenditures for the FIT. Given a FIT rate $\zeta$, the competitive equilibrium is now given by

$$
\begin{gathered}
P(Q)=p=C_{b}{ }^{\prime}\left(Q_{b}\right)+t \\
P(Q)=p=C_{f}{ }^{\prime}\left(Q_{f}\right)+t \\
\zeta=C_{r}{ }^{\prime}\left(Q_{r}\right) \\
{[\zeta-p] Q_{r}=t\left[Q_{b}+Q_{f}\right]}
\end{gathered}
$$

We again study the comparative statics effects of increasing the FIT. The results can be summarized as follows:

Proposition 4: Assume the electricity market is fully competitive and expenditures for the feed-in tariff are collected by a mark-up $t=\left[Q_{b}+Q_{f}\right] /[\zeta-p] Q_{r}$ on the electricity price. Then an increase in the feed-in tariff leads to

$$
\frac{d Q_{b}}{d \zeta}<0, \frac{d Q_{f}}{d \zeta}<0, \frac{d Q_{r}}{d \zeta}>0, \frac{d}{d \zeta}\left(\frac{Q_{r}}{Q}\right)>0, \frac{d t}{d \zeta}>0
$$

The impact on total output and price is ambiguous. If the marginal cost function of the baseline technology is sufficiently flat, the total impact on output will be negative and the market price will increase. 
For a proof, see the appendix. We see that the results are similar to those outlined in Proposition 2 except for the effect on total output, which is now ambiguous. In the case of lump-sum FIT financing, increasing the tariff results in unilaterally subsidizing one type of electricity generation and is therefore bound to induce an increase in total output. Under a mark-up regime, by contrast, total output can rise or fall. This is the case because there are two offsetting effects. The share of RES-E electricity always goes up. However, while lumpsum financing of the feed-in tariff brings about a pure crowding-out effect on conventional electricity, with a positive effect on total output (Proposition 3), a surcharge regime will make conventional electricity more expensive. This may hurt consumers, but since it also provides higher incentives to save energy, it is more efficient for the actual goal of cutting down on total emissions. Note, however, that output is not optimally reduced since flexible energy always goes down, although this is not optimal in general, as shown in Proposition 2. Overall, it can be said that in order to reduce $\mathrm{CO}_{2}$ emissions a FIT combined with a budget-balancing mark-up on the electricity price is less inefficient than financing the tariff in a lump-sum way or by collecting other distorting taxes.

\section{Quota of Renewable Energy}

We now assume that emission reduction is not the government's only goal. It also wants to establish a particular share (quota) of renewable energy in the overall electricity supply. For this purpose, we return to the disaggregate model for a moment. A quota for renewable energy $\beta$ can then be written as

$$
\frac{\sum_{i=1}^{I} q_{r i}}{\sum_{i=1}^{I} q_{r i}+\sum_{j=1}^{J} q_{c j}} \geq \beta
$$

We start by looking at the (constrained) optimal allocation under constraint (22) and then consider decentralization. 


\subsection{The constrained social optimum with an RES-E quota}

The social planner's problem is maximization of (1) subject to constraint (22). For conventional technologies, the first-order complementary slackness conditions are then given by

$$
P(Q)-C_{c j}{ }^{\prime}\left(q_{c j}\right)-\mu \beta \leq 0, \quad\left[P(Q)-C_{c j}{ }^{\prime}\left(q_{c j}\right)-\mu \beta\right] q_{c j}=0,
$$

for the RES-E technologies by

$$
P(Q)-C_{r i}{ }^{\prime}\left(q_{r i}\right)+\mu(1-\beta) \leq 0, \text { and }\left[P(Q)-C_{r i}{ }^{\prime}\left(q_{r i}\right)+\mu(1-\beta)\right] q_{r i}=0 \text {. }
$$

If RES-E technologies produce positive quantities in the optimum, we obtain

$$
C_{r i}{ }^{\prime}\left(q_{r i}\right)=C_{r k}{ }^{\prime}\left(q_{r k}\right)=P(Q)+\mu(1-\beta)
$$

Obviously, it should be equally costly to produce the last unit of electricity for all RES-E sources that produce positive quantities. If $P(Q)-C_{r_{0}}{ }^{\prime}(0)+\mu(1-\beta) \leq 0$ holds for some $i_{0}$, technology $i_{0}$ should not be employed at all. From (25) we also see that the marginal cost of electricity production from RES-E technologies must exceed the consumers' marginal willingness to pay for electricity. In other words, there must be an implicit subsidy for RES-E technologies if the quota for renewable energy is binding. For conventional technologies the contrary is true. There is a gap between marginal cost and the consumers' marginal willingness to pay, which results in an implicit tax. We can summarize this result as follows:

Proposition 5: Assume there is a quota for RES-E only. Then the optimal allocation requires RES-E sources to produce at equal marginal cost above the consumers' marginal WTP for electricity, while the conventional plants produce at (equal) marginal costs below the consumers' marginal WTP. We use $q_{c i}^{*}, q_{r j}^{*}$, and $\mu^{*}$ to denote the optimal levels of all variables. 


\subsection{The impact of increasing the quota}

To study the comparative statics effects of increasing the quota for renewable energy, it suffices to look at the aggregate model, where the first-order conditions for the constrained social optimum are represented by

$$
\begin{gathered}
P(Q)=C_{b}{ }^{\prime}\left(Q_{b}\right)+\mu \beta \\
P(Q)=C_{f}{ }^{\prime}\left(Q_{f}\right)+\mu \beta \\
P(Q)=C_{r}{ }^{\prime}\left(Q_{r}\right)-\mu(1-\beta) \\
(1-\beta) Q_{r}=\beta Q_{b}+\beta Q_{f}
\end{gathered}
$$

Differentiating this system with respect to $\beta$ yields the following result:

Proposition 6: When the quota for renewable energy is increased, we obtain

$$
\frac{d Q_{b}}{d \beta}<0, \quad \frac{d Q_{f}}{d \beta}<0
$$

while the signs of $\frac{d Q_{r}}{d \beta}, \frac{d \mu}{d \beta}$, and $\frac{d Q}{d \beta}$ are ambiguous.

For a proof, see the appendix. Thus, as expected, we see that a higher quota means using fewer conventional energy sources. This reduction is partly induced by crowding out through renewable energy (when the quota is small) and partly by the shadow cost of meeting the quota (when the quota is sufficiently large). To satisfy the quota in that case, the cost of increasing the amount of green electricity may be too high, so that it is cheaper to reduce the amount of conventional energy instead of increasing the amount of renewable energy.

\subsection{Decentralization by (tradable) green certificates}

If there is perfect competition on the electricity market, the quota for RES-E sources can easily be decentralized by creating a market for green certificates. To see this, let us assume 
that no conventional firm $i$ has any RES-E technology of its own but has to buy green certificates denoted by $z_{i}$ to meet the target, i.e.

$$
\frac{z_{i}}{q_{c i}+z_{i}} \geq \beta
$$

Thus the Lagrange function of a conventional utility is given by

$$
L_{i}\left(q_{c i}, z_{i}\right)=p q_{c i}-C_{c i}\left(q_{c i}\right)-\rho z_{i}+\mu_{i}\left[z_{i}(1-\beta)-\beta q_{c i}\right]
$$

where $\rho$ is the market price for tradable green certificates and $\mu_{i}$ is the Lagrange multiplier w.r.t. (31). The RES-E firms maximize profits given by

$$
\pi\left(q_{r j}\right)=p q_{r j}+\rho z_{j}-C_{r j}\left(q_{r j}\right)=[p+\rho] q_{r j}-C_{r j}\left(q_{r j}\right)
$$

The second equality in (33) holds because the number of green certificates $z_{j}$ created by the RES-E firms is equal to the amount of energy they produce, i.e. $z_{j}=q_{r j}$.

The first-order necessary conditions for maximum profit for the conventional firms are then given by

$$
\begin{gathered}
\frac{\partial L}{\partial q_{c i}}=p-C_{c i}{ }^{\prime}\left(q_{c i}\right)-\mu_{i} \beta=0 \\
\frac{\partial L}{\partial z_{i}}=-\rho+\mu_{i}(1-\beta)=0
\end{gathered}
$$

while for the RES-E firms the first-order condition is

$$
\frac{\partial \pi}{\partial z_{j}}=p+\rho-C_{r j}{ }^{\prime}\left(q_{r j}\right)=0
$$

From (35) we obtain $\mu_{i}=\rho /(1-\beta)$ and thus $\mu_{i}=\mu_{i^{\prime}}=\mu$ for all $i$. Accordingly, the equilibrium is determined by the following equations:

$$
\begin{gathered}
P(Q)-C_{c i}{ }^{\prime}\left(q_{c i}\right)=p-C_{c i}{ }^{\prime}\left(q_{c i}\right)=\rho \frac{\beta}{1-\beta} \\
P(Q)-C_{r j}{ }^{\prime}\left(q_{r j}\right)=p-C_{r j}{ }^{\prime}\left(q_{r j}\right)=-\rho
\end{gathered}
$$




$$
\sum_{j=1}^{J} q_{r j}=\sum_{i=1}^{I} z_{i}
$$

Comparing these conditions with the constrained social optimum, we see that the competitive price for green certificates is given by

$$
\rho=\mu^{*}(1-\beta)
$$

We can summarize this finding as follows:

Proposition 7: If the electricity market is competitive and the government wants to implement a quota for RES-E, establishing a market for green certificates will implement the constrained social optimum.

Together with Proposition 6 we obtain:

Corollary 1: Increasing the quota induces less use of fossil fuel energy, while the impact on the quantity of renewable energy, total output, and price is ambiguous.

\subsection{Decentralizing an RES-E quota target by a a feed-in-tariff or a premium system;}

The bulk of the literature discussing policies promoting RES-E favors FITs over tradable green certificates (see e.g. Menanteau, 2003; Haas et al. 2004; Haas et al. 2010; Held 2006; Madlener et al. 2009). Also, the majority of European countries aiming at achieving the $20 \%$ RES-E share use FITs. ${ }^{7}$

In the following, we will show that the constrained social optimum can equally well be implemented by a budget-balanced FIT or by a premium system. In the latter case, instead of a receiving a fully artificial price, the FIT, the RES-E operators sell their electricity on the market but get a subsidy (premium) on top. Let us first study the premium system. For this

\footnotetext{
${ }^{7}$ According to Savin et al. (2012) 65 countries world-wide use FITs, while 18 countries (53 jurisdictions) use quotas or renewable portfolio standards, the less efficient version of a tradable quota system.
} 
purpose, we use $\xi$ to denote the premium and $t$ to denote the mark-up on the conventional firms' cost. Thus the conventional firms' profit is given by

$$
\Pi_{i}\left(q_{c i}\right)=p q_{c i}-C_{c i}\left(q_{c i}\right)-t q_{c i}
$$

while the RES-E firms' profit is given by

$$
\Pi_{j}\left(q_{r j}\right)=[p+\xi] q_{r j}-C_{r j}\left(q_{r j}\right)
$$

The first-order conditions for profit maximization are then written as

$$
\frac{\partial \Pi_{c i}}{\partial q_{c i}}=p-C_{c i}{ }^{\prime}\left(q_{c i}\right)-t=0
$$

and

$$
\frac{\partial \Pi_{r j}}{\partial q_{r j}}=p+\xi-C_{r j}{ }^{\prime}\left(q_{r j}\right)=0
$$

Choosing $t=\mu^{*} \beta$ and $\xi=\mu^{*}(1-\beta)$, we see that (43) and (44) are equivalent to (34) and (36)

Moreover a balanced budget requires

$$
\begin{gathered}
t \sum_{i=1}^{I} q_{c i}=\xi \sum_{j=1}^{J} q_{r j} \\
\Leftrightarrow \quad \mu^{*} \beta \sum_{i=1}^{I} q_{c i}=\mu^{*}(1-\beta) \sum_{j=1}^{J} q_{r j} \\
\Leftrightarrow \quad \beta \sum_{i=1}^{I} q_{c i}=(1-\beta) \sum_{j=1}^{J} q_{r j}
\end{gathered}
$$

Rearranging the last equation yields

$$
\frac{\sum_{i=1}^{I} q_{r i}}{\sum_{i=1}^{I} q_{r i}+\sum_{j=1}^{J} q_{c j}}=\beta
$$

which is the same as (22). Let us denote by $p^{*}, \xi^{*}$, and $t^{*}$ the second-best optimal price, premium, and mark-up decentralizing the social optimum.

To see that under conditions of certainty a FIT is equivalent to a premium system, we can simply choose 


$$
\varsigma^{*}=p^{*}+\xi^{*}
$$

A balanced budget then requires

$$
t \sum_{i=1}^{I} q_{c i}=[\varsigma-p] \sum_{j=1}^{J} q_{r j}=\xi \sum_{j=1}^{J} q_{r j}
$$

which is then equilvalent to (45). So all in all, we obtain

Proposition 8: An RES-E target quota can be decentralized by implementing a uniform budget balanced FIT system, or by a premium system where RES-E operators receive a premium on top of the market price financed by a budget-balancing mark-up on electricity from conventional sources.

For equivalence of the three systems it is important to note that both the premium and the FIT must be uniform. We will study differentiated systems in the next section. Note also that equivalence holds only under certainty. If the electricity market price fluctuates caused by demand and supply shocks, RES-E operators do not adjust their supply under a FIT whereas they partially do so under a premium system and have to fully adjust under TGCs. Proponents of FIT consider this as an advantage of the FIT, because all risk is taken away from RES-E operators. In fact, however, the risk is only shifted to the consumers, and due to suboptimal supply, a welfare loss arises.

\section{Different RES-E Technologies and Technology-specific Feed-in Tariffs}

Most countries employ systems where technology-specific tariff rates are paid for electricity generated by different RES-E. The tariffs are basically adapted to the (marginal) cost of electricity production deriving from different RES-E. The operative rule is: the higher the 
(marginal) production cost, the higher the FIT rate. As an example, Table 1 shows the different tariff rates from Germany and Spain.

\begin{tabular}{|l|l|l|l|}
\hline Type of RES-E & Germany 2000 & Germany 2012 & Spain 2012 \\
\hline Wind on land & $6.2-9.1$ & $8.9-9.9$ & 7.3 \\
\hline PV & $48.1-59.9$ & $18.0-24.5$ & 26.9 \\
\hline Biomass & $8.7-10.2$ & $6.0-25.0$ & 13.1 \\
\hline Geothermal & $7.2-9.0$ & 23.3 & 7.8 \\
\hline Wind offshore & --- & 15.0 & 7.3 \\
\hline $\begin{array}{l}\text { Power \& heat } \\
\text { cogeneration }\end{array}$ & --- & 5.1 & 13.3 \\
\hline
\end{tabular}

Table 1: FIT rates differentiated with respect to sources for selected countries and years (Source: BMU, 2012; CNE, 2013)

Different reasons are given for such policies and we discuss them below. First, however, we analyze the effect of a system of differentiated FITs. For simplicity, we assume that there are only two RES-E technologies (we refer to them as wind power $(W)$ and photovoltaic panels $(P V)$ ) and that there is just one conventional technology $(C)$. We use $C_{W}\left(q_{W}\right)$ and $C_{P V}\left(q_{P V}\right)$ to denote the aggregate cost of producing electricity from the two RES and $C_{c o n}\left(q_{c o n}\right)$ to denote the cost of electricity generation with conventional technologies, i.e. aggregating $C_{b}\left(q_{b}\right)$ and $C_{f}\left(q_{f}\right)$. We further assume that $0<C_{W}{ }^{\prime}(0)<C_{P V}{ }^{\prime}(0)$ and $C_{W}{ }^{\prime}(q)<C_{P V}{ }^{\prime}(q)$ for any output level $q>0$, i.e. producing electricity from PV is more costly than using wind. Moreover, we use $\zeta_{W}$ and $\zeta_{P V}$ to denote the corresponding FIT rates for electricity generated by wind and PV, respectively.

The competitive market equilibrium with The competitive market equilibrium with apportioning of FITs to the electricity price is then given by the following equation system:

$$
P(Q)=p=C_{c o n}{ }^{\prime}\left(Q_{c o n}\right)+t
$$




$$
\begin{gathered}
\zeta_{W}=C_{W}{ }^{\prime}\left(Q_{W}\right) \\
\zeta_{P V}=C_{P V}{ }^{\prime}\left(Q_{P V}\right) \\
\zeta_{W} Q_{W}+\zeta_{P V} Q_{P V}=t\left[Q_{b}+Q_{f}\right]
\end{gathered}
$$

From the previous sections we know that, in the absence of positive externalities, any system with differentiated FITs $\zeta_{W} \neq \zeta_{P V}$ is inefficient for both an emissions target and an RES-E quota target. To analyze the effect of spreading the two tariff rates, we let $\zeta_{P V}$ increase and $\zeta_{W}$ decrease, keeping the total electricity output generated from RES-E constant, i.e. $Q_{W}+Q_{P V}=\bar{Q}_{r}$. We thus differentiate (49) - (52) w.r.t. $\zeta_{P V}$. Writing $t^{\prime}=d t / d \zeta_{P V}$ and so on, we obtain

$$
\begin{gathered}
P^{\prime}(Q)\left[Q_{c o n}{ }^{\prime}+Q_{W}{ }^{\prime}+Q_{P V}{ }^{\prime}\right]=C_{c o n}{ }^{\prime}\left(Q_{c o n}\right) Q_{c o n}{ }^{\prime}+t^{\prime} \\
\zeta_{w}{ }^{\prime}=C_{W}{ }^{\prime}\left(Q_{W}\right) Q_{W}{ }^{\prime} \\
1=C_{P V}{ }^{\prime \prime}\left(Q_{P V}\right) Q_{P V}{ }^{\prime} \\
\zeta_{W}{ }^{\prime} Q_{W}+Q_{P V}+\zeta_{W} Q_{W}{ }^{\prime}+\zeta_{P V} Q_{P V}{ }^{\prime}=t^{\prime} Q_{c}+t Q_{c}{ }^{\prime} \\
Q_{W}{ }^{\prime}+Q_{P V}{ }^{\prime}=0
\end{gathered}
$$

Solving this system for $Q_{c o n}{ }^{\prime} \equiv d Q_{c o n} / d \zeta_{P V}, \zeta_{W}{ }^{\prime} \equiv d \zeta_{W} / d \zeta_{P V}$ and so on yields

$$
\begin{gathered}
\frac{d Q_{c o n}}{d \varsigma_{P V}}=\frac{C_{P V}^{\prime \prime}\left(Q_{P V}\right) Q_{P V}-C_{W}^{\prime \prime}\left(Q_{W}\right) Q_{W}+\varsigma_{P V}-\varsigma_{W}}{-C_{P V}^{\prime \prime}\left(Q_{P V}\right)\left[Q_{c o n}\left[C_{c o n}^{\prime \prime}\left(Q_{c o n}\right)-P^{\prime}(Q)\right]-t\right]} \\
\frac{d Q_{P V}}{d \varsigma_{P V}}=\frac{1}{C_{P V}^{\prime \prime}\left(Q_{P V}\right)}>0 \\
\frac{d Q_{W}}{d \varsigma_{P V}}=\frac{-1}{C_{P V}^{\prime \prime}\left(Q_{P V}\right)}<0 \\
\frac{d t}{d \varsigma_{P V}}=\frac{-\left[C_{c o n}^{\prime \prime}\left(Q_{c o n}\right)-P^{\prime}(Q)\right]\left[C_{P V}^{\prime \prime}\left(Q_{P V}\right) Q_{P V}-C_{W}^{\prime \prime}\left(Q_{W}\right) Q_{W}+\varsigma_{P V}-\varsigma_{W}\right]}{-C_{P V}^{\prime \prime}\left(Q_{P V}\right)\left[Q_{c o n}\left[C_{c o n}^{\prime \prime}\left(Q_{c o n}\right)-P^{\prime}(Q)\right]-t\right]} \\
=-\left[C_{c o n}^{\prime \prime}\left(Q_{c o n}\right)-P^{\prime}(Q)\right] \frac{d Q_{c o n}}{d \varsigma_{P V}}
\end{gathered}
$$


These expressions give rise to the following result:

Proposition 9: Increasing one FIT rate, say $\zeta_{P V}$, and at the same time lowering the other FIT rate $\zeta_{W}$ while keeping the total amount of RES-E electricity constant induces the following effects:

i) The amount of electricity generated from PV will increase, while the amount of electricity generated from wind power will decrease (see eqs. (59) and (60)).

ii) The impact on the amount of electricity generated from conventional (fossil-fuel) technologies, $Q_{c o n}$, is ambiguous (see eq. (58)).

iii) The impact on the electricity mark-up $t$ and therefore on the market price is also ambiguous. The impact on $t$ is positive (negative) if and only if the impact on $Q_{c o n}$ is negative (see eq (61)).

So contrary to what the champions of differentiated FITs claim, the mark-up will not necessarily decrease with the spread of FITs. Furthermore, even if the mark-up $t$ decreases, the incidence of both conventional electricity and emissions will increase, an effect that the use of renewable energy is supposed to prevent. 


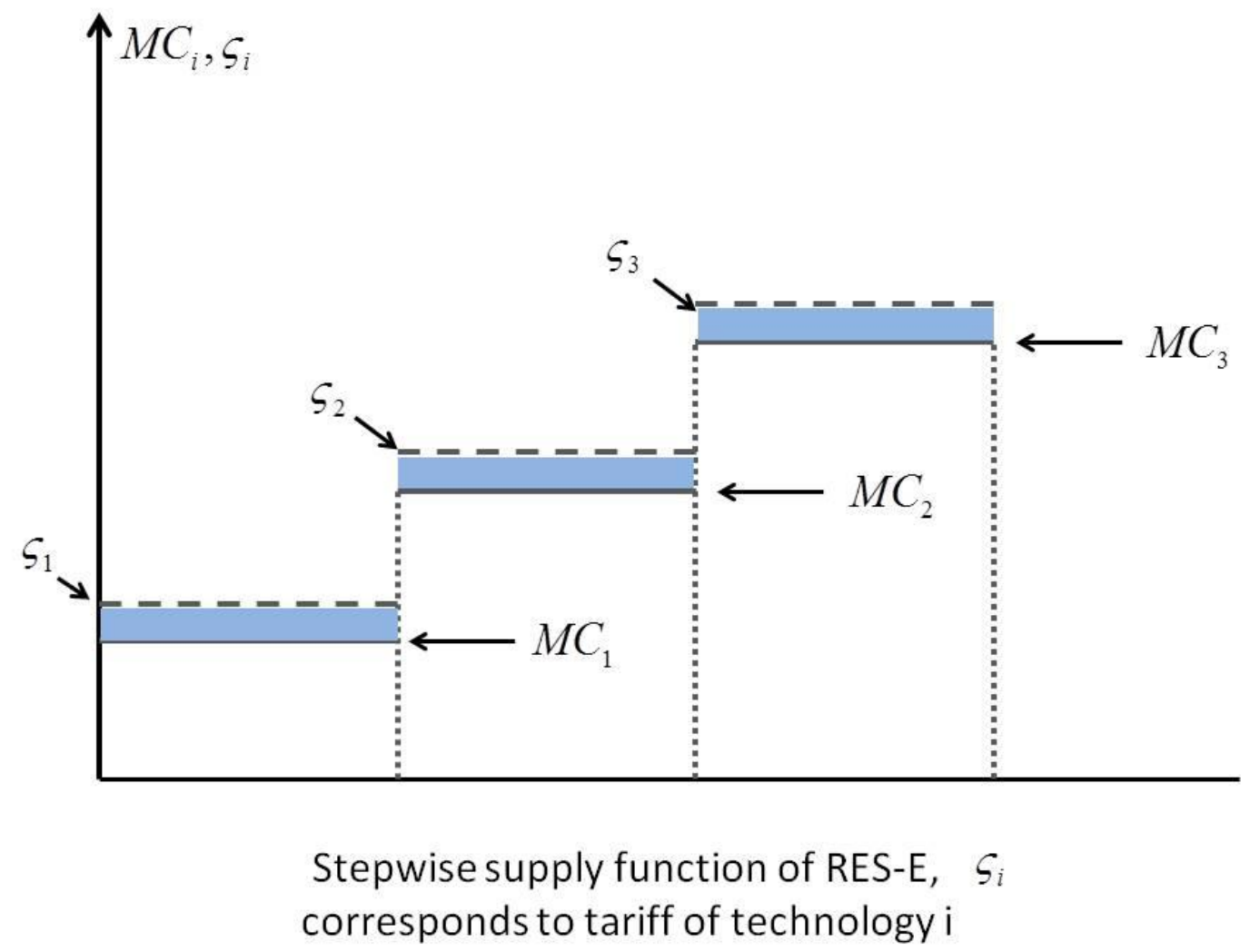

Figure 1: Technology-specific feed-in tariffs with stepwise supply function of RES-E. $\varsigma_{i}$ corresponds to the feed-in tariff of technology $i$ and $M C_{i}$ to its marginal production cost.

Auer et al. (2009), Haas et al. (2010), and various other authors argue that a system of differentiated FIT rates leads to lower costs than a uniform FIT and thus to a lower mark-up on the electricity price. Figure 1 reproduces this argument. The implicit assumption behind that figure is that there are constant marginal costs per unit of electricity and technology, and that there is a fixed capacity for each technology. Neither assumption holds in reality. Space for all three major RES-E technologies (wind turbines, PV panels, bio-gas electricity power plants) is not really limited (except by legal constraints), and turbine locations close to the sea shore are more effective than remote locations in the hinterlands, particularly in mountainous areas. This means that costs will increase per unit (megawatt hour), the less effective the locations are. A similar argument holds for PV panels. Locations in the south (of Europe) are 
more effective, so their deployment there is more efficient than in the north. Accordingly, the assumption of an increasing supply curve for each technology is more in line with the real world than the model behind Figure 1. For simplicity's sake, Figures 2 and 3 display the case of only two technologies, say wind power and PV. In Figure 2 there is a uniform tariff, at which electricity from PV will not be supplied on the market. The cost of producing the first unit at the most favorable site exceeds the uniform FIT rate. In Figure 3, the FIT rate for wind has been lowered while the rate for PV has been increased, thus reducing the supply of wind power and providing incentives for PV to enter the market. By construction, total output is the same as under the uniform tariff. In this case, however, savings in expenditures for wind electricity are lower than the expenditures for PV. Of course, the opposite may be the case. This depends on both the marginal cost for the cheapest unit and the elasticity of the supply curve. The most severe fault in Figure 1 is certainly the assumption of fixed capacities for the specific technologies. It overlooks the fact that less effective wind locations are still much more effective than good PV locations.

Note also that part iii) of Proposition 9 tells us that even if the effect of differentiating the FIT on the mark-up is ambiguous, one unwanted effect cannot be avoided. By differentiating FITs, either the mark-up goes up, and for consumers electricity gets more expensive, or the amount of fossil fuel energy increases, which is bad for the climate. 


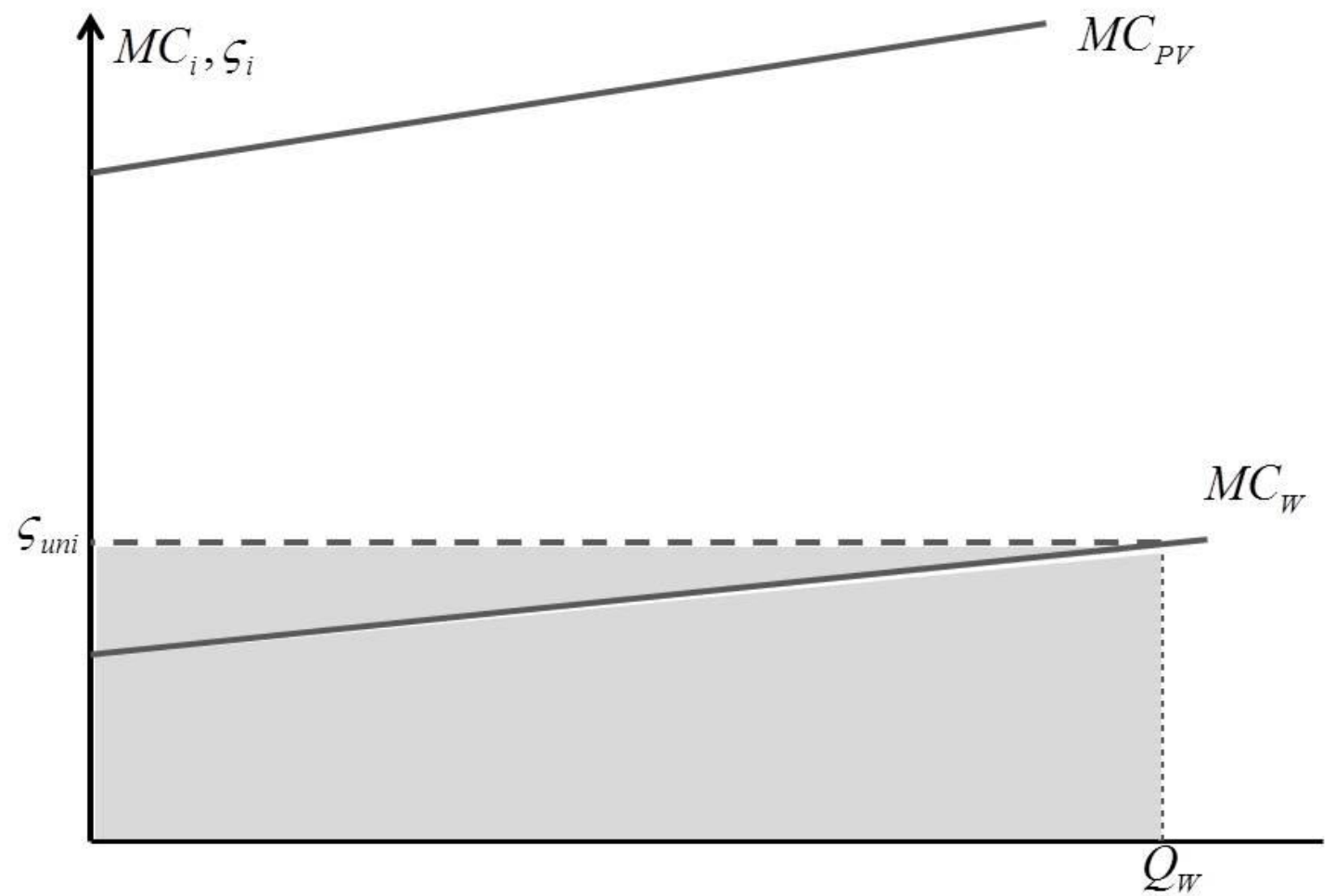

Figure 2: Increasing supply functions for different RESs. Uniform tariff. Grey area: cost of FIT. No electricity supply from PV. 


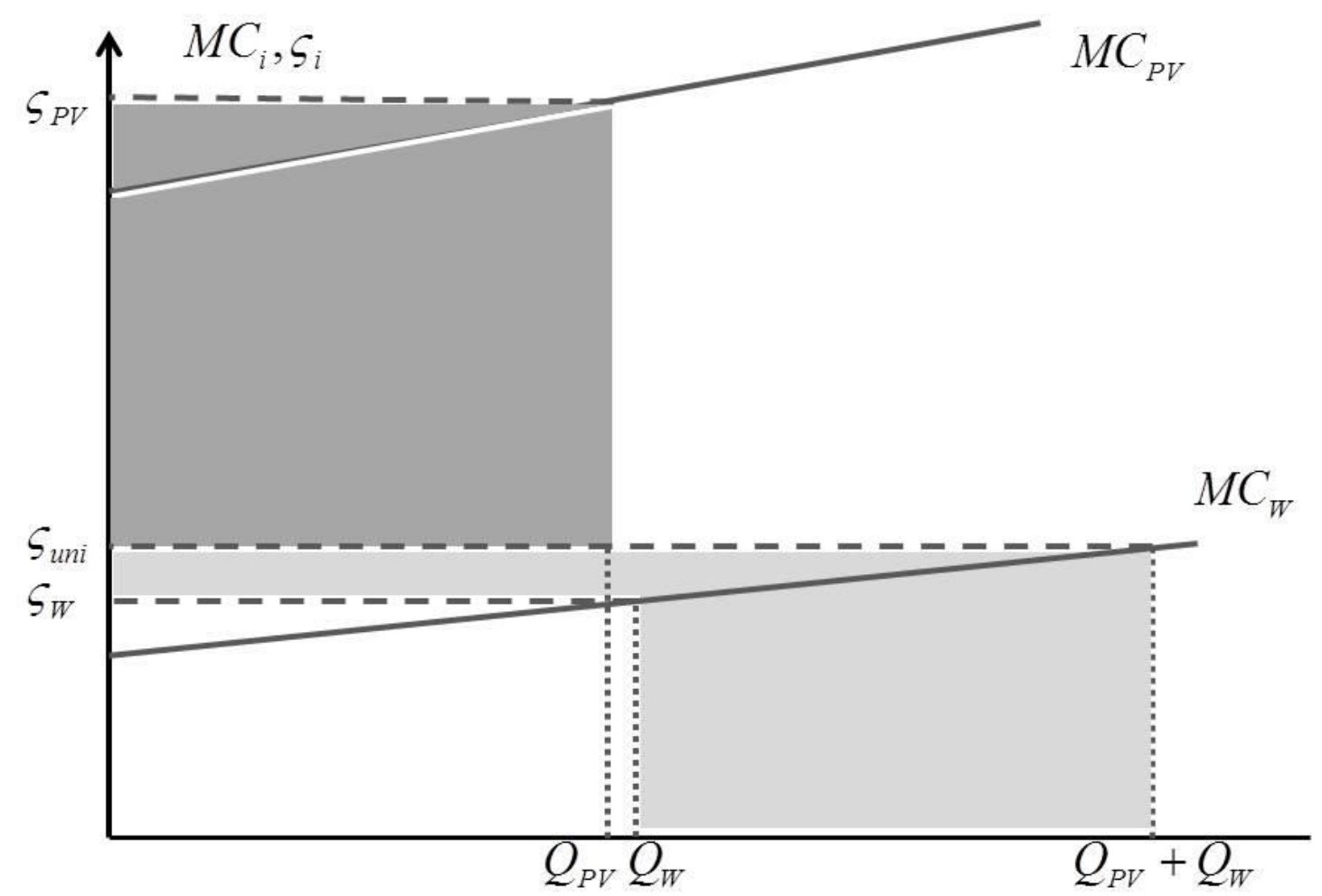

Figure 3: Differentiated tariffs. Additional expenditures for PV (dark grey area) exceed cost savings (light grey area) for wind power.

\section{Learning-by-doing and Technology Spillovers}

So far, we have been looking at policy instruments from a static perspective. One argument frequently advanced in public debate is that high FIT rates are necessary to bring down production costs through learning-by-doing. This argument, however, poses a number of questions. Why should there be market failure, why do RES-E equipment producers not internalize learning effects by themselves, and why does the market provide insufficient rates of learning? One answer might be that there are learning spillovers that are not internalized by the market. Petrakis et al. (1997) show that if learning effects are purely private and markets are competitive, firms will produce sufficiently large outputs in a first phase of production and market introduction, and there will be no market failure. Both Bläsi and Requate (2009) for 
the case of competitive energy markets, and Reichenbach and Requate (2012) for the case of conventional electricity producers exercising market power, consider a two-period model where learning effects occur in the production of RES-E equipment. An RES-E equipment producer's output level in the first period does not only lower its own second-period cost, but also benefits other RES-E equipment producers. The authors show that in such a case a subsidy on RES-E equipment is efficiency-enhancing. The subsidy level should be equal to the marginal cost reduction through spillovers. FITs, by contrast, do not target the product where the learning spillovers occur, but rather affect a product downstream in the production chain. Reichenbach and Requate (2012) show that as a substitute for direct subsidies on learning spillovers a FIT is largely ineffective and creates major welfare losses.

Real FIT systems, however, are not tied to the marginal effects of learning spillovers. They are adapted to the competitive disadvantage, i.e. the difference between market price and marginal cost of the RES-E operator. Moreover, the marginal spillover effect is usually independent of the level of marginal production cost. Accordingly, the differentiated systems currently employed lack any theoretical foundation.

Moreover, as Schmalensee (2008) points out, to date there is no empirical investigation of the question whether such learning spillovers actually exist and, if so, how large they are. Nemet (2006) argues that cost reductions in RES-E equipment production are not necessarily due to learning effects. Cost reductions over time can also be driven by economies of scale and employee turnover. In the case of PV, Nemet finds that learning from experience only weakly explains the most important factors such as plant size, module efficiency and the cost of silicon. 


\section{Promoting Renewable Energy not only for the Sake of Emission}

\section{Reductions?}

In its renewable energy directive (EC 2009), the European Commission names the reduction of greenhouse gases as the number one reason for the need to increase the share of RES-E. Besides this, however, it also lists a number of other targets it is aiming at by promoting the deployment of RES-E. Essentially, these targets are i) making countries less dependent on energy imports, ${ }^{8}$ ii) providing new employment opportunities and creating green jobs, iii) establishing economic growth through innovation, iv) creating opportunities for competitive energy policy ${ }^{9}$. The directive also claims the existence of positive ancillary benefits from the deployment of RES-E such as a) positive impact on regional and local development opportunities and b) export prospects. ${ }^{10}$ However, as we shall see in the following, all of these additional targets and the existence of ancillary benefits are questionable.

Independence from energy imports. Tribes, peoples, and nations have engaged in trade since the beginning of mankind. People buy or import goods that they do not have or can only produce at comparatively high cost. Therefore reducing imports is not a meaningful target in itself. Concerning fossil fuel resources (with the exception of crude oil and oil products), ${ }^{11}$ prices have turned out to be rather stable. Both natural gas and coal deposits are abundant and ubiquitous (including new natural-gas deposits such as shale gas). So, despite recent regional conflicts (such as the Russian-Ukrainian one) the risk of sudden price hikes is relatively low. Even though prices may increase moderately, markets will typically react to scarcity and geopolitical risks. Moreover, except for the Middle East, oil is hardly used anymore to fuel power plants. ${ }^{12}$ On the other hand, the production of RES-E equipment such as PV panels and wind

\footnotetext{
${ }^{8}$ Introduction to DIRECTIVE 2009/28/EC, paragraph (1).

${ }^{9}$ Ibid. paragraph (3).

${ }^{10}$ Ibid., paragraph (4).

${ }^{11}$ Here we observe a $200 \%$ real price increase over the last 12 years (InvestmentMine (2013) and own calculations).

${ }^{12}$ The share of oil in electricity production is $5 \%$ worldwide and $3 \%$ in the EU.
} 
turbines creates new dependencies on other non-renewable resources such as light and heavy rare earth elements. ${ }^{13}$ Finally, the supply of RES-E is highly volatile and has to be backed up by flexible, relatively expensive gas-turbine power plants. So switching from fossil fuel imports to RES-E merely shifts the risk of resource dependence and may create new price volatility through the stochastic supply of wind and sun (an issue that is beyond the theoretical model presented in this article).

Providing new employment opportunities and creating green jobs. While southern Europe currently faces high unemployment rates, this is not the case in central Europe where engineers and high skill works have become a scarce resource. While promoting RES-E will indeed create new jobs in specialist segments of the economy, it is doubtful whether the total employment effect is positive. As shown theoretically in this article, and as experienced painfully in Germany, FITs sharply push up electricity prices. The economy as a whole typically reacts quite sensibly to energy price increases by lowering output and thus laying off workers. Recent CGE studies show the overall employment effects triggered by the deployment of RES-E to be typically negative (Böhringer et al. 2012, Böhringer et al. 2013). High employment figures in one particular sector of any economy is not a meaningful target in itself, and it makes even less sense if they are achieved at the cost of increasing unemployment on the aggregate level. Moreover, there is no clear division between "green" and "brown" jobs. Creating so-called green jobs can result in shifting from one externality to another.

Innovation and green growth through green technologies. Similarly, innovation is not a meaningful target in itself either. While promoting so-called green sectors may result in growth for these sectors, it is questionable whether green policy triggers higher aggregate growth rates and higher TFP. The bulk of the endogenous growth literature predicts that

\footnotetext{
${ }^{13}$ Especially magnets for modern wind turbines use large amounts of $\mathrm{Nd}$. Batteries, catalytic converters, and other so-called environmental technologies often require up to a dozen different rare-earth elements.
} 
environmental policy leads to a change in the direction of technological progress (Acemoglu et al. 2012) but does not typically predict higher aggregate growth (Aghion and Howitt 1998).

Regional development and export opportunities. Whether certain products are developed in large factories with strong increasing returns to scale (such as cars and aircraft) or whether production is spatially spread out, as is the case with agricultural products, is a matter of technology. Agglomeration is not necessarily a bad thing, nor spatially spread-out production a blessing. The example of Germany's transition to a higher share of RES-E ("Energiewende") shows that electricity transportation costs are in fact increased by spreading out electricity production, while the production of RES-E equipment is concentrated in a few locations. Moreover, Europe has turned into a major importer for PV panels. With respect to wind turbine production, the picture is mixed. While European producers have lost market shares, notably to Chinese and Indian producers, some firms, especially from Denmark and Germany, have increased their export volumes while others face shrinking demand. ${ }^{14}$

While it is true that market failure with respect to excessive $\mathrm{CO}_{2}$ emissions is indeed huge, there is no evidence for market failure with respect to inefficiently high energy imports. As for other targets such as reducing unemployment or boosting regional development, the promotion of RES-E is not a very effective instrument and may even be harmful. It is highly unlikely that the unemployment problem in Southern Europe can be solved by large-scale deployment of RES-E. The Tinbergen rule (Tinbergen 1952) is still valid. It is little effective to apply a single instrument to achieving several different targets.

\section{Conclusions}

Supporters of RES-E who argue in favor of discriminatory, technology-specific FIT systems seem to ignore some basic economic principles. The first of those principles is the equalmarginal-cost principle, meaning that it should be equally costly for the marginal producer

\footnotetext{
${ }^{14}$ U.S. Department of Energy (2011), Burger (2012)
} 
(facility) to produce the last unit of a homogenous good (such as electricity). Supporters of technology-specific FIT systems evade the equal-marginal-cost principle by hinting at the major cost-decreasing potential of learning-by-doing effects. However, they forget that rational producers have an incentive to internalize cost decreases through private learning-bydoing effects on their own. In the absence of learning spillovers, learning-by-doing does not create market failure, and there is no need for policy intervention. If learning spillovers exist, which may well be the case, it is the marginal spillover effect that should determine possible subsidy rates, not the present average or marginal cost of producing electricity from RES-E. Third, even if we accept the existence of learning spillovers, internalizing such spillovers also incurs costs. It is not only the marginal effect that matters, but also the total cost (in terms of subsidies) of making a certain technology competitive. It is far from clear that making a certain technology competitive, notably the deployment of PV in northern Europe, would stand up to a cost/benefit analysis. This is doubly true if we take into account other opportunities of cutting down on carbon emissions in developing countries. Also, the additional target of achieving a particular share of renewable energy only increases the cost of achieving a particular emission target and does not reduce emissions any further.

Our conclusion is that for a pure emission target a cap-and-trade system is sufficient. All other measures are wasteful except for non-internalized spillover effects. Proponents of technology-specific FIT systems argue that additional support for renewable energy is necessary to bring costs down and, in a second step, tighten emission caps. This argument is flawed for several reasons. First, it is much more efficient to reverse the order: tighten the emission cap first, and let the market look for opportunities to cut back emissions at the lowest possible cost. Second, the benefits of a national support policy for FITs accrue mostly to foreign RES-E equipment producers and to other countries within the cap-and-trade system (say the EU-ETS), which then free-ride on decreasing permit prices. 
We have been looking at a simple deterministic model. In reality, an additional difficulty arises through the volatility of RES-E supply. This creates additional costs as a result of short supply in phases where there is little wind or sunlight. This then has to be substituted for by flexible fossil-fuel power plants. Regulation energy of this kind is especially expensive because the capacities of the respective power plants (typically gas turbines) are usually not exhausted, so capital costs are high. On the other hand, the volatility of RES-E supply causes excess supply of electricity in situations when wind and sun supply is high. This causes net stabilization costs reflected by negative market prices for electricity. Negative market prices, however, are a sure sign of market inefficiency.

Countries that pay high subsidies for RES-E claim to be front runners and hope that others will emulate them. If it turns out that by domestically increasing electricity prices, firms will relocate production to less ambitious countries, the opposite effect may materialize. Such a development may be interpreted as proof that the quick replacement of fossil fuels by certain particularly expensive RES-E does not work and thus discourage developing countries from engaging in carbon mitigation. Therefore countries ambitious about reducing $\mathrm{CO}_{2}$ emissions should rethink the lessons from economics, reduce $\mathrm{CO}_{2}$ emissions at the lowest possible economic cost, and thus reduce as many $\mathrm{CO}_{2}$ units with limited financial resources. This can best be achieved by cap-and-trade or by a carbon tax. Other market interacting measures only increase the cost without saving additional $\mathrm{CO}_{2}$.

\section{Appendix}

Proof of Proposition 2: Differentiating (7) - (10) with respect to $\bar{E}$, we can write the resulting equation system in matrix form (omitting the function arguments) as

$$
\left[\begin{array}{cccc}
P^{\prime}-C_{b} " & P^{\prime} & P^{\prime} & -\alpha_{b} \\
P^{\prime} & P^{\prime}-C_{r} " & P^{\prime} & 0 \\
P^{\prime} & P^{\prime} & P^{\prime}-C_{f} " & -\alpha_{f} \\
\alpha_{b} & 0 & \alpha_{f} & 0
\end{array}\right]\left[\begin{array}{c}
d Q_{b} / d \bar{E} \\
d Q_{r} / d \bar{E} \\
d Q_{f} / d \bar{E} \\
d \lambda / d \bar{E}
\end{array}\right]=\left[\begin{array}{l}
0 \\
0 \\
0 \\
1
\end{array}\right]
$$


Let $\operatorname{Det}(M)=\left[\alpha_{f}^{2} C_{b} "+\alpha_{b}^{2} C_{f} "\right]\left[C_{r} "-P^{\prime}\right]-C_{r} " P^{\prime}\left[\alpha_{b}-\alpha_{f}\right]^{2}>0$ be the determinant of the matrix in (62). Solving in (62), we obtain

$$
\begin{gathered}
\frac{d Q_{b}}{d \bar{E}}=\frac{\left[\alpha_{f}-\alpha_{b}\right] C_{r} " P^{\prime}+\alpha_{b} C_{f} "\left[C_{r} "-P^{\prime}\right]}{\operatorname{Det}(M)}>0 \\
\frac{d Q_{f}}{d \bar{E}}=\frac{\left[\alpha_{b}-\alpha_{f}\right] C_{r} " P^{\prime}+\alpha_{f} C_{b} "\left[C_{r} "-P^{\prime}\right]}{\operatorname{Det}(M)} \\
\frac{d Q_{r}}{d \bar{E}}=\frac{\alpha_{f} C_{b} "+\alpha_{b} C_{f} "}{\operatorname{Det}(M)}<0 \\
\frac{d \lambda}{d \bar{E}}=\frac{P^{\prime}\left[C_{b} " C_{r} "+C_{b} " C_{f} "+C_{f} " C_{r} "\right]-C_{b} " C_{r} " C_{f} "}{\operatorname{Det}(M)}<0
\end{gathered}
$$

While (64) is ambiguous as to the sign, we see immediately by adding (63) and (64) that

$$
\frac{d\left[Q_{b}+Q_{f}\right]}{d \bar{E}}=\frac{\alpha_{f} C_{b} "\left[C_{r} "-P^{\prime}\right]}{\operatorname{Det}(M)}>0
$$

Finally, for the share of renewable energy we obtain

$$
\frac{d\left[Q_{r} /\left(Q_{b}+Q_{f}+Q_{r}\right)\right]}{d \bar{E}}=\frac{P^{\prime}}{C_{r}{ }^{\prime}}<0
$$

That the sign of $\frac{d Q_{f}}{d \bar{E}}$ is indeed ambiguous can be shown by example. Choose $P(Q)=A-B Q$ and $C_{i}\left(Q_{i}\right)=\frac{c_{i}}{2} Q_{i}^{2}$ and let $A=100.0, B=1.0, c_{b}=0.1, c_{f}=0.3, c_{r}=1.0$, $\alpha_{b}=1.0, \alpha_{f}=0.5$. If we now tighten the emission cap from $\bar{E}=50$ to $\bar{E}=40$, we will find that $Q_{f}$ increases from 16.67 to 37.78 . If we choose $c_{f}=0.9$, keeping all other parameters as before and tightening the emission cap from $\bar{E}=50$ to $\bar{E}=40$, we will find that $Q_{f}$ decreases from 18.13 to $17.10 .^{15}$

Proof of Proposition 3: Differentiating (12) - (14) with respect to $\zeta$ yields in matrix form

\footnotetext{
${ }^{15}$ Detailed calculations of all values can be obtained from the author on request.
} 


$$
\left[\begin{array}{ccc}
P^{\prime}-C_{b} " & P^{\prime} & P^{\prime} \\
P^{\prime} & P^{\prime}-C_{f} " & P^{\prime} \\
0 & 0 & C_{r}{ }^{\prime}
\end{array}\right]\left[\begin{array}{l}
d Q_{b} / d \zeta \\
d Q_{f} / d \zeta \\
d Q_{r} / d \zeta
\end{array}\right]=\left[\begin{array}{l}
0 \\
0 \\
1
\end{array}\right]
$$

Let $\operatorname{Det}(M)=C_{r} "\left[C_{b} " C_{r} "-P^{\prime}\left(C_{b} "+C_{f} "\right)\right]>0$ be the determinant of the matrix in (69).

Solving this equation, we obtain

$$
\begin{gathered}
\frac{d Q_{b}}{d \zeta}=\frac{C_{f} " P^{\prime}}{\operatorname{Det}(M)}<0 \\
\frac{d Q_{f}}{d \zeta}=\frac{C_{b} " P^{\prime}}{\operatorname{Det}(M)}<0 \\
\frac{d Q_{r}}{d \zeta}=\frac{C_{b} " C_{f} "-P^{\prime}\left[C_{b} "+C_{f} "\right]}{\operatorname{Det}(M)}>0
\end{gathered}
$$

From this we derive, after simplification,

$$
\begin{gathered}
\frac{d Q}{d \zeta}=\frac{C_{b} " C_{f} "}{\operatorname{Det}(M)}>0 \\
\frac{d}{d \zeta}\left(\frac{Q_{r}}{Q}\right)=\frac{-P^{\prime} Q\left[C_{f} "+C_{b} "\right]+C_{b} " C_{f} "\left[Q_{b}+Q_{f}\right]}{\operatorname{Det}(M)}>0
\end{gathered}
$$

\section{Proof of Proposition 4}

Differentiating (17) - (20) with respect to $\zeta$ yields in matrix form

$$
\left[\begin{array}{cccc}
P^{\prime}-C_{b} " & P^{\prime} & P^{\prime} & -1 \\
P^{\prime} & P^{\prime}-C_{f} " & P^{\prime} & -1 \\
0 & 0 & C_{r} " & 0 \\
t+P^{\prime} Q_{r} & t+P^{\prime} Q_{r} & p+P^{\prime} Q_{r}-\zeta & Q_{b}+Q_{f}
\end{array}\right]\left[\begin{array}{c}
d Q_{b} / d \zeta \\
d Q_{f} / d \zeta \\
d Q_{r} / d \zeta \\
d t / d \zeta
\end{array}\right]=\left[\begin{array}{c}
0 \\
0 \\
1 \\
Q_{r}
\end{array}\right]
$$

By stability of the competitive equilibrium the determinant of the matrix $\operatorname{Det}(M)=C_{r} "\left[\left[C_{f} "+C_{b} "\right]\left[-P^{\prime} \cdot Q-t\right]+C_{f} " C_{b} "\left[Q_{b}+Q_{f}\right]\right]$ must be positive. Solving (75), we obtain

$$
\frac{d Q_{b}}{d \zeta}=\frac{C_{f} "\left[P^{\prime} Q\right]-C_{r} " Q_{r}+p-\zeta}{\operatorname{Det}(M)}<0
$$




$$
\begin{gathered}
\frac{d Q_{f}}{d \zeta}=\frac{C_{b} "\left[P^{\prime} Q\right]-C_{r}{ }^{\prime} Q_{r}+p-\zeta}{\operatorname{Det}(M)}<0 \\
\frac{d Q_{r}}{d \zeta}=\frac{1}{C_{r} "}>0 \\
\frac{d Q}{d \zeta}=\frac{C_{b}{ }^{\prime \prime} C_{f} "\left[Q_{b}+Q_{f}\right]+\left[C_{b} "+C_{f} "\right]\left[p-\zeta-C_{r} " Q_{r}-t\right]}{\operatorname{Det}(M)} \\
\frac{d}{d \zeta}\left(\frac{Q_{r}}{Q}\right)=\frac{Q\left[-C_{f} " P^{\prime} \cdot Q^{\prime}+t\right]+C_{b} "\left[C_{f} "\left[Q_{b}+Q_{f}\right]-P^{\prime} \cdot Q-t\right]}{\operatorname{det}(M)} \\
\frac{d t}{d \zeta}=\frac{-Q_{r}\left[C_{b}{ }^{\prime \prime}+C_{f} "\right]\left[C_{r} " Q_{r}+t+\zeta-p\right]}{\operatorname{det}(M)}>0 \\
\operatorname{det}(M)
\end{gathered}
$$

To show that the sign of $d Q / d \zeta$ is ambiguous, we again choose linear (inverse) demand $P(Q)=A-B Q$ and cost functions of the type $C_{j}(q)=c_{j 0} q+c_{j 1} q^{2} / 2$ for $j=b, f, r$.

Parameters are selected according to $A=100.0, B=1.0, c_{b 0}=0.1, c_{b 1}=0.1, c_{f 0}=0.2$, $c_{f 1}=0.3, c_{r 0}=1.0, c_{r 1}=0.05$.

Then for $\zeta=8(\zeta=10, \zeta=12)$ we obtain $Q=380(Q=385, \zeta=380)$.

\section{Proof of Proposition 6}

By differentiating (26) - (29) with respect to $\beta$ we can write the resulting equation system in matrix form (omitting the function arguments) as

$$
\left[\begin{array}{cccc}
P^{\prime}-C_{b} " & P^{\prime} & P^{\prime} & -\beta \\
P^{\prime} & P^{\prime}-C_{f} " & P^{\prime} & -\beta \\
P^{\prime} & P^{\prime} & P^{\prime}-C_{r} " & 1-\beta \\
\beta & \beta & 1-\beta & 0
\end{array}\right]\left[\begin{array}{c}
d Q_{b} / d \beta \\
d Q_{r} / d E \beta \\
d Q_{f} / d E \beta \\
d \mu / d E \beta
\end{array}\right]=\left[\begin{array}{c}
\mu \\
\mu \\
\mu \\
Q
\end{array}\right]
$$

Writing the determinant of the matrix in (82) as $\operatorname{Det}[M]=-C_{b} " C_{f} "[1-\beta]^{2}+\beta^{2}\left[C_{b} "+C_{f} "\right]\left[P^{\prime}-C_{r} "\right]<0$ for short and solving (82), we obtain

$$
\frac{d Q_{b}}{d \beta}=\frac{C_{f} "\left[\mu(1-\beta)+Q\left[\beta C_{r} "-P\right]\right.}{\operatorname{Det}[M]}<0
$$




$$
\begin{gathered}
\frac{d Q_{f}}{d \beta}=\frac{C_{b} "\left[\mu(1-\beta)+Q\left[\beta C_{r} "-P^{\prime}\right]\right.}{\operatorname{Det}[M]}<0 \\
\frac{d Q_{r}}{d \beta}=\frac{\left[C_{f} " P^{\prime}+C_{b} "\left[P^{\prime}-C_{f} "\right]\right] Q+\beta\left[\mu\left[C_{b} "+C_{f} "\right]+C_{b} " C_{f} " Q\right]}{\operatorname{Det}[M]} \\
\frac{d \mu}{d \beta}=\frac{C_{r} "\left[C_{b} "+C_{f} "\right] \beta \mu+C_{r} "\left[C_{f} "+C_{b} "\right] P^{\prime} Q-C_{b} "\left[C_{f} "(1-\beta) \mu+\left[C_{r} "-P '\right] Q\right]}{\operatorname{Det}[M]} \\
\frac{d Q}{d \beta}=\frac{C_{f} "\left[\mu+\beta C_{r} " Q\right]+C_{b} "\left[\mu-\left[(1-\beta) C_{f} "+\beta C_{r} "\right] Q\right]}{\operatorname{Det}[M]}
\end{gathered}
$$

To show the ambiguity of $\frac{d Q_{r}}{d \beta}, \frac{d \mu}{d \beta}$, and $\frac{d Q}{d \beta}$ we take the functional forms as in the proof of Proposition 2 and choose $A=100.0, B=1.0, c_{b}=0.1, c_{f}=0.3, c_{r}=1.0$. Increasing $\beta$ leads to strictly increasing $Q_{r}$ decreasing total output and increasing shadow cost of the RESE. Taking a less elastic inverse demand function by selecting $B=0.2$, we can show $Q_{r}$ and the shadow cost $\mu$ to be inverted U-shaped. Choosing $B=1.5$, we can see that for small but binding $\beta$, total output is first increasing then decreasing when $\beta$ is increased.

\section{References}

Abbasi SA, Abbasi N (2000) The likely adverse environmental impacts of renewable energy sources. Applied Energy 65:121-144

Acemoglu D, Aghion P, Bursztyn L, Hemous D (2012) The Environment and Directed Technical Change. American Economic Review 102 (1):131-166

Aghion P, Howitt P (1998) Endogenous Growth Theory. Cambridge, MA. MIT-Press

Auer H, Resch G, Haas R, Ragwitz M (2009) Regulatory instruments to deliver the full potential of renewable energy sources efficiently. European Review of Energy Markets 3:91-124 
Bläsi A, Requate T (2009) Feed-in-Tariffs for Electricity from Renewable Energy Resources to Move Down the Learning Curve? Public Finance and Management 10(2):213-250

BMU 2012 (German Federal Department for the Environment, habitat protection, and nuclear power security) http://www.bmu.de/service/publikationen/downloads/details/artikel/ erneuerbare-energien-gesetz-eeg-2012/

Böhringer C, Rivers NJ, Rutherford T, Wigle R (2012) Green Jobs and renewable energy policies: employment impacts of Ontario's Feed-in Tariff. The B.E. Journal of Economic Analysis and Policy 12, Article 25, DOI 10.1515/1935-1682.3217

Böhringer C, Keller A, van der Warf E (2013) Are green hopes too rosy? Employment and welfare impacts of renewable energy promotion. Energy Economics (forthcoming).

Burger B (2012) Electricity Production from solar and wind in Germany. Fraunhofer Institute for solar energy systems ISE. http://www.ise.fraunhofer.de/en/ downloads-english/pdffiles-english/news\%20/electricity production from solar and wind in germany 2012.pdf

CNE (2013) Liquidación de las primas equivalentes, primas, incentivos y complementos a las instalaciones de producción de energía eléctrica en régimen especial mes de producción: 12/2012, Comisión Nacional de Energía, dirección de inspección, liquidaciones y compensaciones, February 2, 2013

EC (2009) Directive 2009/28/EC of the European Parliament and of the Council of 23 April 2009 on the promotion of the use of energy from renewable sources and amending and subsequently repealing Directives 2001/77/EC and 2003/30/EC

Haas R, Eichhammer W, Huber C. Langniss O, Lorenzoni A, Madlener R, Menateau P Morthorst P, Martins A, Oniszek A, Schleich J, Smith A, Vass Z, Verbruggen A (2004) How to promote renewable energy systems successfully and effectively. Energy Policy 32:833-839 
Haas R, Resch G, Panzer C, Busch S, Ragwitz M, Held A (2010) Efficiency and effectiveness of promotion systems for electricity generation from renewable energy sources Lessons from EU countries. Energy. http://public.tuwien.ac.at/files/ PubDat_193135.pdf

Held A, Haas R, Ragwitz M (2006) On the success of policy strategies for the promotion of electricity from renewable energy sources in the EU. Energy \& Environment 17:849868

Jensen, SG, Skytte K (2002) Interaction between the power and green certificate markets. Energy Policy 30:425-435

Klessmann C, Nabe C, Burges K (2008) Pros and cons of exposing renewables to electricity market risks - A comparison of the market integration approaches in Germany, Spain and the UK. Energy Policy 36:3646-3661

Madlener R, Gao W, Neustadt I, Zweifel P (2009) Promoting renewable electricity generation in imperfect markets: price vs. quantity policies. University of Zurich Socioeconomic Institute, Working Paper 0809

Menanteau P, Finon D, Lamy ML (2003) Prices versus quantities: choosing policies for promoting the development of renewable energy. Energy Policy 31:799-812

Midttun A, Gautesen K (2007) Feed in or certificates, competition or complementary? Combining a static efficiency and a dynamic innovation perspective on the greening of the energy industry. Energy Policy 35:1419-1422

Mitchell C, Bauknecht D, Connor, PM (2006) Effectiveness through risk reduction: a comparison of the renewable obligation in England and Wales and the feed-in system in Germany. Energy Policy 34:297-308

Morthorst PE (2003a) National environmental targets and international emission reductions instruments. Energy Policy 31:73-83 
Morthorst PE (2003b) A green certificate market combined with liberalized power market. Energy Policy 31:1393-1402

Nemet G (2006) Beyond the learning curve: factors influencing cost reductions in photovoltaics. Energy Policy 34:3218-3232

Petrakis E, Rasmusen E, Roy E (1997) The learning curve in a competitive industry. The RAND Journal of Economics 28:248-268

Reichenbach J, Requate T (2012) Subsidies for Renewable Energies in the Presence of Learning Effects and Market Power. Resource and Energy Economics 34:236-254

Savin JL (lead author) et al. (2012) Renewables 2012. Global Status Report. REN21 secretariat Paris

Schalensee R (2012) Evaluating Policies to Increase Electricity Generation from Renewable Energy. Review of Environmental Economics and Policy 6:45-64

Selin H, VanDeever S (2009) Changing Climates in North American Politics, Institutions, Policymaking, and Multilevel Governance. The MIT Press, Cambridge MA

Tamas MM, Shrestha SO, Zhou H (2010) Feed-in tariff and tradable green certificate in oligopoly. Energy Policy 38:4040-4047

Tinbergern J (1952) On the Theory of Economic Policy. Amsterdam. North-Holland

Tsoutsos T, Frantzeskaki N, Gekas V (2005) Environmental impacts from solar energy technologies. Energy Policy 33:289-296

U.S. Department of Energy (2012) 2011 Wind technology market reports. www1.eere.energy.gov/wind/pdfs/2011_wind_technologies_market_report.pdf

Zhou H, Tamas MM (2010) Impacts of integration of production of black and green energy. Energy Economics 32:220-226

http://www.infomine.com/investment/metal-prices/coal/ 